\title{
The Idea Innovation Network and Research Arenas: The Brazilian Case of the INCT INDI-Saúde
}

\author{
Leandro Rodrigo Canto Bonfim ${ }^{1}$ \\ Sandro Aparecido Gonçalves ${ }^{2}$ \\ Andréa Paula Segatto ${ }^{3}$
}

\begin{abstract}
${ }^{1}$ Programa de Pós-Graduação em Administração, Universidade Federal do Paraná (PPGADM/UFPR). Av. Pref. Lothário Meissner, 632, 2º andar - Jardim Botânico, Curitiba, PR, Brazil 80210-170, E-mail: lrcbonfim@ufpr.br ${ }^{2}$ Instituto Brasileiro de Estudos e Pesquisas Sociais (IBEPES), Curitiba, Brazil. Phone: +55 41 9-9995-3048, E-mail: sandro1313@uol.com.br
\end{abstract}

${ }^{3}$ Programa de Pós-Graduação em Administração, Universidade Federal do Paraná (PPGADM/UFPR). Av. Pref. Lothário Meissner, 632, 2 andar - Jardim Botânico, Curitiba, PR, Brazil 80210-170, Phone: +55 41 3360-4381, E-mail: aps@ufpr.br

\begin{abstract}
The aim of this article was to study how a successful innovative network on molecular diagnosis for public health in Brazil, emerged as an idea innovation network with six functional research arenas. We adopted a qualitative case study with in-depth interviews and documentary data. We found that the idea innovation network model was predictive of innovation and technological development, presenting connectedness within and between arenas. We extended the model by finding that the structure of relationship within arenas are not the same as of between arenas, with the former being composed of stronger ties and closer networks, while the latter was formed by sparser networks of relationships, connected through structural holes. We also contributed by showing that the functional research arenas of an idea innovation network may not be equally developed, as we found three stages of development of the research areas: consolidated, advanced development stage, and preliminary development stage.
\end{abstract}

Keywords: Research arenas. Technological development. Innovation. Innovation networks. Public health.

***Working paper: doi 10.17605/OSF.IO/5FNT8 


\section{Introduction}

The pressure from the idea that innovation is necessary for maintaining competitiveness on the market each day more globalized (Porter, 2000) led to the emergence of several organizational models for achieving innovation. Despite the variety of prescriptive models for innovation, only a few are empirically validated (Van de Ven, Angle, \& Poole, 2000). Thus, the replication of these models without the due concern with the institutional context in which they are expected to produce innovation outcomes it is not unusual. The simple replication of these models without the due concern with the institutional context in which they are supposed to produce innovation outcomes it is not uncommon. Regarding interorganizational network models for innovation, experiences like the Silicon Valley in the United States (Castilla, Hwang, Granovetter, \& Granovetter, 2000) and the Italian Industrial Districts (Belussi \& Sedita, 2009) are translated to another context. For instance, in Brazil, the local productive arrangements model were translated from the Marshallian model of industrial districts (Jacometti, Gonçalves, \& Castro, 2014).

Besides, innovation is not restricted only to technical advances in new technologies, products, and services. According to Van de Ven (1986), we may consider innovation on administrative spheres in the cases of creation of new procedures, governance policies, and organizational forms. The innovation as a new organizational form is the case for Hage and Hollingsworth's (2000) idea innovation network model, which advanced from previous innovation models by stating that research arenas are not geographically bounded (Kline \& Rosenberg, 1986; Van Waarden \& Oosterwijck, 2006). In this sense, the flows of knowledge and information are located on networks organized in six functional research arenas interconnected both internally and externally. This principle is appropriate when considering the current globalized context we live in, being effective for implementing public policies for the induction of innovation networks (Hage, Mote, \& Jordan, 2013).

The Brazilian case we analyzed was located in the context of the INCT Program (Institutos Nacionais de Ciência e Tecnologia, or National Institutes of Science and Technology). It was a government program aiming to induce networks of collaboration for frontier research and innovation in international levels involving universities, top research institutes, funding agencies, and private organizations on strategic fields of the National System of Science, Technology, and Innovation (Rezende, 2011). Given the specific demands of the National System of Health (SUS, Sistema Único de Saúde, the costless Brazilian public system for health care) for reducing their technological dependence of imported technology and production inputs on diagnostic field, a group of researchers from Fiocruz Paraná proposed the creation of the INCT 
National Institute for Innovation on Diagnosis for Public Health (INDI-Saúde). This area was considered strategic by the Federal government due to the high levels of costs for the public system.

In this context, our aim in this article was to analyze a successful innovative network, the INDI-Saúde network, with the lens of Hage and Hollingswoth's (2000) idea innovation network models. The investigation was set in a Brazilian context of innovation for public health, which is characterized by the concentration of the technological development in public research institutes and public universities, with a majority of government funding, but with an increasing participation of the private organizations in recent public policies programs (Bonfim, Gonçalves, Moreira, \& Jacometti, 2016). In this sense, we intend to contribute for the reduction of the lack of empirical validated predictive models for studying innovation and technology development in strategic areas for public policy, such as public health.

Our results showed that idea innovation networks may be a useful organizational form for technological development and innovation on emerging market contexts, such as Brazil, when presenting connectedness within and between research arenas. We found that this pattern emerged after a high amount of resources were invested, potentializing the capability of development of the network. We not only provided empirical analysis for the idea innovation model, but we also extended it through relevant theoretical contributions. We found that the patterns of relationships within arenas are not similar to the patterns of relationships between arenas. While the former consisted of dense and closed network of relationships with stronger ties, the later was essentially formed through structural holes and weaker ties that are characteristics of sparser network forms (Burt, 1992; Coleman, 1988; Granovetter, 1973; Krackhardt, 1992). Furthermore, we found that the functional research arenas of an idea innovation network may not be equally developed, as we found three developmental stages of research areas: consolidated, advanced developmental stage, and preliminary development stage.

Thus, this article is structured as follows. We started presenting the theoretical foundations of the idea innovation network model. Then, we presented the research procedures adopted for studying the case of INDI-Saúde's network. On the research and discussion session, we presented historical and contextual evidence, followed by our analysis of network shape and network connectedness, and finally, we analyzed the relationships within and between the research arenas and the stages of development of each arena. We concluded the article with final considerations with the main finding and contributions, the limitations, and future possibilities for research. 


\section{Theoretical background}

The institutional configuration of a society may both constrain and facilitate its innovativeness, influencing the way firms to innovate and the intensiveness of innovations (Hollingsworth, 2000). In this sense, societies embedded in more rigid institutional contexts, as Germany, for example, are more likely to produce incremental knowledge and innovation rather than radical innovation and technological disruptions (Hollingsworth, 2000; Kraft, Stank, \& Dewenter, 2011).

When comparing German Academy with the American counterpart, Hollingsworth (2000) noticed that some characteristics of German society lead to incremental innovation: (a), the turnover rates in German organizations are low, creating a stability concerning long-term decision, favoring knowledge exploitation, while in America, while in American organizations higher levels of turnover rates lead to higher levels of knowledge and ideas exploration; (b) the sources of funding in Germany are usually long-term loans, while in the US the venture capital systems are well developed, stimulating risk-taking for radical innovation; (c) in the German educational system, the professors are public servants with guaranteed and fixed wages, what lead them to avoid risk taking, while in the American system the professors are financially incentivized to produce relevant discoveries through their research projects, since it confers considerable increases in their incomes.

Building on the idea that innovations are dependent on the institutional context in which organizations are embedded in, Hage and his colleagues (Hage \& Hollingsworth, 2000; Hage et al., 2013) argued that the current institutional contexts pressure organizations to specialize and differentiate each day more. Thus, arenas of specialty are created, and organizations specialize themselves inside each arena (but not necessarily in only one), forming strategic alliances with other specialized organizations in arenas outside their domains when they perceive it is necessary for the innovation to be successful within their industrial sectors. As defined by the authors, idea innovation networks are characterized by the relationships and research activities occurring in each of the six research arenas specified in Table 1 , and the connectedness within and among these research arenas (Hage \& Hollingsworth, 2000, p. 972). The dominant arenas on the network depend on the institutional context and the industrial sector that the organizations are operating (Hage \& Hollingsworth, 2000; Hage et al., 2013).

\begin{tabular}{ll}
\hline Functional arena & Definition \\
\hline Basic research & $\begin{array}{l}\text { Experimental or theoretical work undertaken primarily to acquire new knowledge } \\
\text { of the underlying foundations of phenomena and observable facts, without any } \\
\text { application or use in view. }\end{array}$ \\
Applied research & $\begin{array}{l}\text { Original investigation undertaken in order to acquire new knowledge. It is, however, } \\
\text { directed primarily towards a specific practical aim or objective. }\end{array}$
\end{tabular}



Product development or product
innovation

Production research or process innovation

Quality control research

Commercialization research
Systematic work, drawing on existing knowledge gained from research and practical experience, that is directed to producing new materials, products and devices, including prototypes.

Research to design new manufacturing products or process.

Research aimed to improve the quality of products as well as research in order better to understand and control the effects of products.

Research designed to understand the needs of customers or to improve the distribution channels.

Table 1. Functional research arenas of idea innovation networks (Hage \& Hollingsworth, 2000, p. 980).

Hage and Hollingsworth (2000) presented two basic properties for the analysis of idea innovation networks (Table 2): the shape and the strength of connectedness within and among the research arenas. The shape is defined by the amount of research activities within and between the network arenas. The network connectedness represents the extent in which the actors embedded in the networks are connected, exchanging information and knowledge. In this sense, connectedness is a critical point for the model, since specialization and differentiation lead to fragmentation of knowledge, demanding the communication to be more frequent and efficient. Hage and Hollingsworth (2000) argued that the more frequent and intense communication among individual researchers, work groups, and organizations occur within and between research arenas, the more and faster tacit knowledge and ideas are communicated, enhancing the likelihood of radical innovation.

\section{Frame of analysis for the idea innovation networks}

Network shape

- Number of researchers (technicians, scientists, and researchers) working on a problem

- Extent of research expenditures from distinct sources (public and private)

- Distinct types and quantities of results (ideas, articles, patents, machinery, quality control instruments, and so forth)

\section{Network connectedness}

- Transfer of people from one research group to another, both within and among organizations

- Joint research projects involving face-to-face collaboration among researchers, as distinct from long-distance collaboration

- Joint publications

- The strength of managerial, financial, and research ties among organizations in joint-venture

- The strength of ties among actors in research consortia

Table 2. Composing terms of the analytical framework for the idea innovation networks. Based on Hage and Hollingsworth (2000, pp. 985-986). 
The relevance of tacit knowledge in the process of radical innovation resides in the fact that "a considerable amount of tacit knowledge is necessary before much codified [explicit] knowledge can be comprehended and transferred" (Hage \& Hollingsworth, 2000, p. 985). In this sense, face-to-face communication potentializes radical innovation. Regarding incremental innovation, codified knowledge becomes more relevant than tacit, since it is based on existing products and processes. Furthermore, we argue that for communication to be rich and effective, there is the need for communication of both tacit and explicit knowledge (Hage \& Hollingsworth, 2000).

Despite not mentioning the optimal forms of structural organization for networks, the idea innovation model presents aspects of the two most disseminated social embeddedness perspectives (Figure 1). Concerning the connection between arenas, the network might be sparse with structural holes connecting every arena through weak ties (Burt, 1992; Granovetter, 1973). This network configuration is favorable to knowledge and information flows and the exploration that are characteristic of hyperdynamic industrial sectors such as semiconductors (Castilla et al., 2000; Rowley, Behrens, \& Krackhardt, 2000) and biotechnology (Powell, Koput, \& Smith-Doerr, 1996), with high levels of innovativeness and high demand for radical innovation.

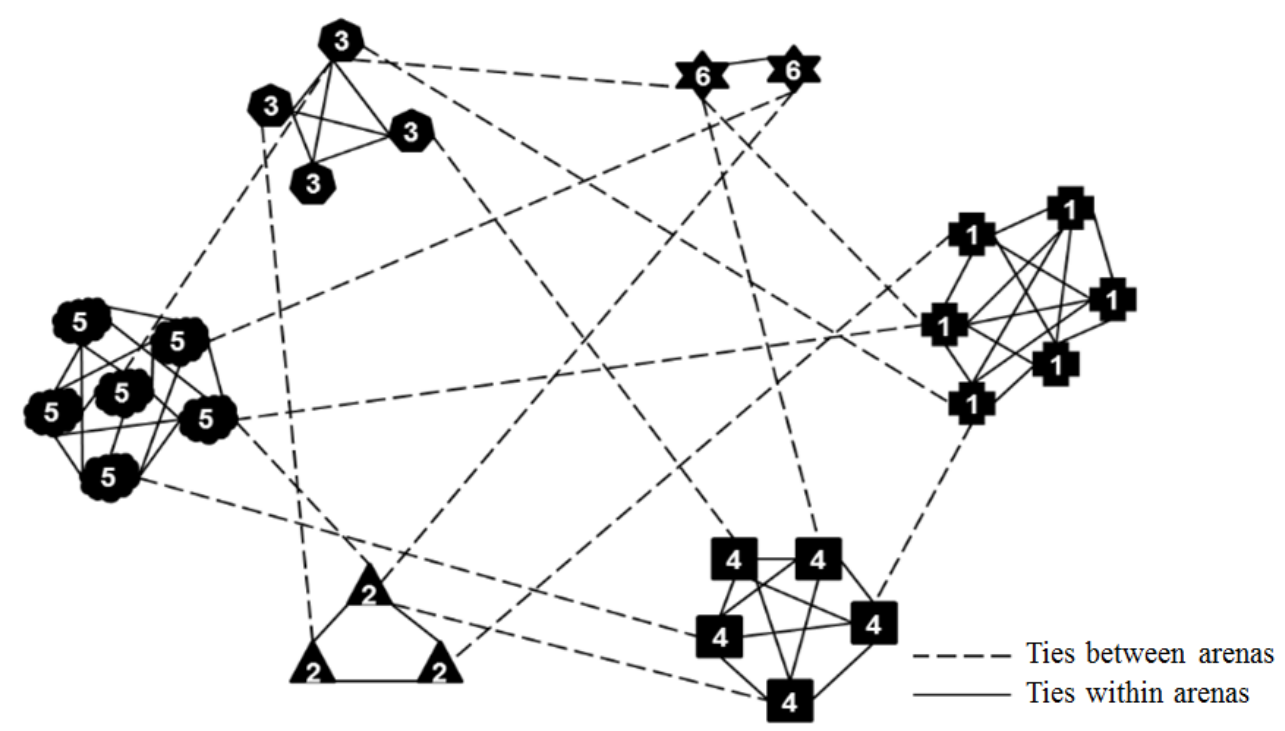

Figure 1. Connections within and between arenas on idea innovation networks graphically represented. The authors (2017)

Regarding the ties within arenas, high levels of density and network closeness (Coleman, 1988) provide greater knowledge diversity and better flow of knowledge. The relational trust provided by strong ties (Krackhardt, 1992) are favorable for 
knowledge exploitation, what is aligned with the high levels of specializations of each arena, in which "because of the greater focus, solutions to research problems are more quickly found" (Hage et al., 2013, p. 210).

The mode of coordination is another matter of concern regarding idea innovation networks. There are four possible modes (Hage \& Hollingsworth, 2000): (a) a single arena in a single organization; (b) multiple arenas in a single organization; (c) a single arena in multiple organizations; (d) multiple arenas in multiple organizations. We argue that it is in the last mode of coordination, in which the level of complexity is high, that radical innovation may take place. Beyond recognizing that interorganizational networks are the locus of innovation, we state that the integration within and between areas also confers legitimation for the innovation efforts (Hage et al., 2013; Powell et al., 1996). In this sense, even if a single organization can concentrate investments through specific departments in each arena, in practice, the majority of this efforts are not successful due to the lack of support for legitimation from interorganizational peers (Cusumano, Mylonadis, \& Rosenbloom, 1992).

Moreover, Hage, Mote, and Jordan (2013) proposed that the idea innovation network model may be adopted as a public policy for promoting innovation in specific industrial areas based on the evolution of science and technological knowledge. In this sense, public policies based on the idea innovation network model may be able to meet the demands of the institutional (e.g. eco-friendly products) and technical environment (e.g. efficient resources allocation). Considering this model as a predictor of innovation, the authors argued that governments may be catalysts of innovation networks, inducting them with public and private participation. Thus, the development of this networks "can be self-forming, but when occurs, it is likely to take place slowly, resulting in a decline in the rate of radical product and process innovation in that sector" (Hage et al., 2013, p. 206).

\section{Research data and methods}

We conducted our investigation between 2013 and 2014 as part of research about the development of Fiocruz Paraná's network as a hub for innovation and technological development in biotechnology applied to public health in Brazil. Our research was exploratory and essentially qualitative. We adopted the case study as research strategy with a cross-sectional temporal cohort with longitudinal approximations through documents and interviewees' memories as a source of evidence. 
We opted for investigating the INDI-Saúde, centered in the Fiocruz Paraná arrangement because this case presented characteristic features when compared with other initiatives performed in Brazil. Furthermore, (a) the case was a potential empirical application of the theoretical model of idea innovation networks (Hage \& Hollingsworth, 2000), with the six basic research arenas and the connectivity among them; (b) Fiocruz is an internationally influential public research organization in the biotechnology and epidemiology areas (Prithwiraj, James, \& Tarun, 2012); (c) Fiocruz Paraná mode of organization in networks is distinct of their peer Fiocruz unities in Brazil (hierarchical/vertical integrated); (d) the recent timing of the formation of Fiocruz Paraná (starting in 1999) provided conditions for collecting data without major constraints regarding network memory.

Thus, the research procedure was threefold. The first step was exploratory, intending to locate the history of formation and configuration of Fiocruz Paraná as an idea innovation network in the institutional context of the Brazilian National System of Innovation. We conducted an unstructured interview with an upper echelon manager of the INCT INDI-Saúde with strategic relevance for the network management. After analyzing this exploratory interview, we developed a semistructured interview guide that would be adopted for conducting the other interviews with other members of the network during the research process. In sum, we conducted six in-depth interviews with different members of the strategic management of the network (Table 3). Additionally, we maintained intense communication between researchers and participants during the research process for crossing all the information.

\begin{tabular}{|c|c|c|c|c|}
\hline \multicolumn{5}{|c|}{ Data collection (interviews) } \\
\hline ID & Organization & $\begin{array}{l}\text { Number of } \\
\text { interviews }\end{array}$ & Audio records & $\begin{array}{l}\text { Additional } \\
\text { documents }\end{array}$ \\
\hline Informant 1 & IBMP & 2 & 76min / 120min (not recorded) & Yes \\
\hline Informant 2 & IBMP & 1 & $40 \mathrm{~min}$ & No \\
\hline Informant 3 & UTFPR & 1 & $38 \mathrm{~min}$ & No \\
\hline Informant 4 & ICC/Fiocruz & 1 & $31 \mathrm{~min}$ & No \\
\hline \multirow[t]{2}{*}{ Informant 5} & UFPR/Tecpar & 1 & 60min (not recorded) & Yes \\
\hline & Total & 6 & $365 \mathrm{~min}$ & - \\
\hline
\end{tabular}

Table 3. Data collection: interviewees and amount of data

We collected data until we perceived the achievement of the theoretical saturation criteria (Flick, 2009), i.e., when the marginal gains resulting of each new interview were minimal considering the patterns of answers and the novelty of the information gathered. Regarding data analysis, we adopted the thematic content analysis (Gibbs, 2007). We created codes based on both theoretical basis and empirical basis, considering that these approaches are not mutually excluding (Gibbs, 2007). We created a code list in advance containing the theoretical themes we expected to find on the discourses of the 
interviewees, complementing it with emerging codes identified when analyzing the data (final list of 77 codes). After coding, the next step was categorizing the data. In this stage, data analysis pass from a descriptive to an analytical and theoretical level, where we grouped Interviewees' reports per correlated themes (Gibbs, 2007). For reliability and validity purposes, we triangulated the data analysis between researchers (first and second authors), returned the transcripts for the participants to confirm the validity of the content, and confronted interview data with secondary data (Merriam, 2009).

The second step was to analyze the INCT INDI-Saúde in the light of the idea innovation framework (Hage \& Hollingsworth, 2000) using documentary data (formal documents, archives, online information, and so forth). We assessed the model through network shape and network connectedness. Following Hage and Hollingsworth's (2000) propositions, we assessed network form through the amount of research activities within and between the network arenas, i.e., (i) the number of researchers working on a problem, (ii) the extent of research expenditures from distinct sources, and (iii) the distinct types and quantities of results. Concerning network connectedness, we assessed the extent in which the actors embedded in the networks are connected, exchanging information and knowledge. In this sense, we evaluated (i) the transfer of people from one research group to another, both within and among organizations, (ii) the joint research projects involving face-to-face collaboration among researchers, as distinct from long-distance collaboration, and (iii) the joint publications.

In this phase of the research, we adopted the social network analysis (SNA) methods for data analysis with the support of UCINET VI software (Borgatti, Everett, \& Freeman, 2002). Thus, we organized the data in sociometric matrices for building the sociograms presented in the analysis with the support of NetDraw software (Borgatti, 2002). The valued matrix provided us to analyze the strength of ties between the actors and the visualization of the network core-periphery relations according to actors' degree centrality. We elaborated another valued matrix for analyzing network connectedness regarding joint publications. Alike the former matrix, the valued matrix provided to visualize the publication network strength of ties and core-periphery relations.

In the third step of the research, we qualitatively assessed and attributed each actor of the network according to the functional research arenas they were related. Additionally, we analyzed the connectedness of the actors within and between the arenas. We developed the analysis technique based on a binary affiliation matrix (2-mode) that we built through documentary (reports, publications, research projects, electronic sites, and so forth) and interview data (Borgatti \& Everett, 1997; Hanneman \& Riddle, 2005). In this sense, we followed the Hage and Hollingsworth's (2000) criteria for placing each organization inside the research arenas. In the operationalization, if an organization was part of a given arena, 
we placed it with the code 1 in the matrix, and if it was not part of a given arena, we placed it with the 0 code. In this analysis, a single organization could be located in a single or multiple arenas. For avoiding biases, we did not have considered organizations that we could not identify their participation in any research arenas through documentary or interview data.

For characterizing the idea innovation network and the relationships between and within arenas, we conducted a 2-mode correspondence analysis, since this technique was adequate for binary attribute matrices (Hanneman \& Riddle, 2005). Besides its adequacy for affiliation matrices. However, as noticed by Borgatti and Everett (1997), the application of 2mode correspondence map analysis was not sufficient for mapping the research arenas and its members. The first concern was regarding the inaccuracy caused by the 2-dimensionality of the correspondence map; the second was that the distance in correspondence analysis is not Euclidian. After analyzing the map, we performed the bipartite graph analysis, since it is considered a viable alternative for 2-mode correspondence analysis (Borgatti \& Everett, 1997), providing accurate identification of which actors attend to each event, or in our case, which organizations are related to which research arenas.

Finally, for assessing the research arenas stage of development, we also decided to perform a core-periphery blockmodeling analysis. Given that blockmodels are "a partition of actors in the network into discrete subsets called positions", in which there is "for each pair of positions a statement of the presence or absence of a tie within or between the positions on each of the relations" (Wasserman \& Faust, 1994, p. 395), this technique is ideal for multi-relational social network analysis.

\section{Results and Discussion}

\section{The antecedents of the INDI-Saúde's idea innovation network}

The embryo of the idea innovation network was on 1999. In that year, a leading group of molecular biology researchers from the Gene Expression Laboratory of the Oswaldo Cruz Institute (IOC), in Fiocruz Rio de Janeiro, founded the Institute for Molecular Biology at Paraná (IBMP). These researchers were responsible for the development of a biochip for DNA sequencing of the protozoa carrier of the Chagas Disease, the Trypanosoma cruzi. As narrated by the research informants, there were unique conditions at that time providing the formation of a center for excellence in the research and development in the field of molecular biology in the city of Curitiba, Brazil. 
The actors created the IBMP by means of an agreement between the Brazilian Federal and Paraná State governments. In the Federal government side, the participating organization was Fiocruz, while at state level government, the partner organization was the Technological Institute of Paraná (Tecpar). The IBMP was created as a Civil Society Organization of Public Interest (CSOP, or OSCIP, in Portuguese), providing the newly founded organization with the administrative flexibility necessary for it to become a reference in technological development and innovation in the area of diagnosis applied to public health (Krieger, Souza, Alvarez, Ferreira, \& Moreira, 2013).

We found that the foundation of the IBMP was surrounded by a period of instability in the historical and institutional context of public health. At the national level, the Brazilian Federal government was engaged in "Patent War" (Loyola, 2008), in which the Brazilian Ministry of Health was trying the compulsory licensing of several medicines for the treatment of HIV carriers and AIDS patients, especially the Efavirenz antiretroviral (ARV). The intent was to reduce the costs of free distribution of the medicines cocktail by the National System of Health (SUS). At the international level, the contamination of hemophiliacs in France with HIV and Hepatitis C through donated blood was still reverberating. As a consequence, the Brazilian Ministry of Health determined the development and implementation of the Nucleic Acid Tests (NAT) for detection of HIV and HCV viruses in every sample of donated blood before ant blood transfusion. The NAT tests should replace the outdated technology adopted at the time, the Enzyme-Linked Immunosorbent Assay test (ELISA) (Krieger et al., 2013; Rezaie et al., 2008).

The adoption of the new technology was achieved in 2006 with the creation of the Technological Consortium FiocruzTecpar-Hemobrás (Brazilian Enterprise of Hemoderivatives and Biotechnology). The consortium built a production plant for the NAT tests, being operated by the IBMP and supplying the total national demand for the tests in both the SUS and private markets. These molecular tests were developed by the IBMP in association with Bio-Manguinhos' Fiocruz unity through technology transfer from Qiagen (Germany), starting to be produced in the plant between 2010 and 2011 with a production of about 3 million samples at the time (Krieger et al., 2013). According to the participants' narratives, the ties created in this project between IBMP and Bio-Manguinhos, along with the previous ties of the IBMP researchers with the Graduate Program in Molecular Biology at the Federal University of Paraná (UFPR) were fundamental for the creation and consolidation of the Fiocruz Paraná unity, the Instituto Carlos Chagas (ICC), in 2008.

Given the development of a high scientific qualification team and the increasing demand of technology from the Ministry of Health, Fiocruz Paraná (ICC and IBMP) reached out the Physics Department at UFPR and the Department of Electrical Engineering at Technological Federal University of Paraná (UTFPR) for elaborating and submitting a project for the call 
from the Ministry of Science, Technology and Innovation (MCT\&I) and the National Council for Scientific and Technological Development (CNPq) in the scope of the National Institutes of Science and Technology (INCTs) program.

The project led to the creation of the INCT INDI-Saúde, intending to develop national technology of diagnostical multitests with liquid microarray and with the Dual Path Platform® (DPP). The decision to create the INDI-Saúde resulted from network actors' strategic and political decisions. The INDI-Saúde provided them with the possibility of advancing several projects that were being developed within IBMP and ICC, especially given the guarantee from the government of buying every molecular test kit produced by the INDI-Saúde.

With the consolidation of the Technological Consortium and the INDI-Saúde by 2008, the network originated several new projects regarding molecular biology, forming a research network of collaboration presented in the sociogram depicted in Figure 2. In this sociogram we represent the projects INDI-Saúde, Stork Network (Rede Cegonha), Sepsis Network, RISH-Sibratec, the European-Brazilian Consortia Point-of-Care Diagnostics for Tropical Diseases (PodiTrodi), Liquid Microarray, Neglected Diseases, Cancer Project, Brucellosis, Epidemiologic Surveillance, Nanobiotechnology for Development, Prototyping, and Product Validation for the SUS (NanoSUS), and Fibrine Glue. As we show on the sociogram (Figure 2), ICC, IBMP, and UFPR are at the core of the network with strong ties among themselves, and the other organizations are on the periphery of the network.

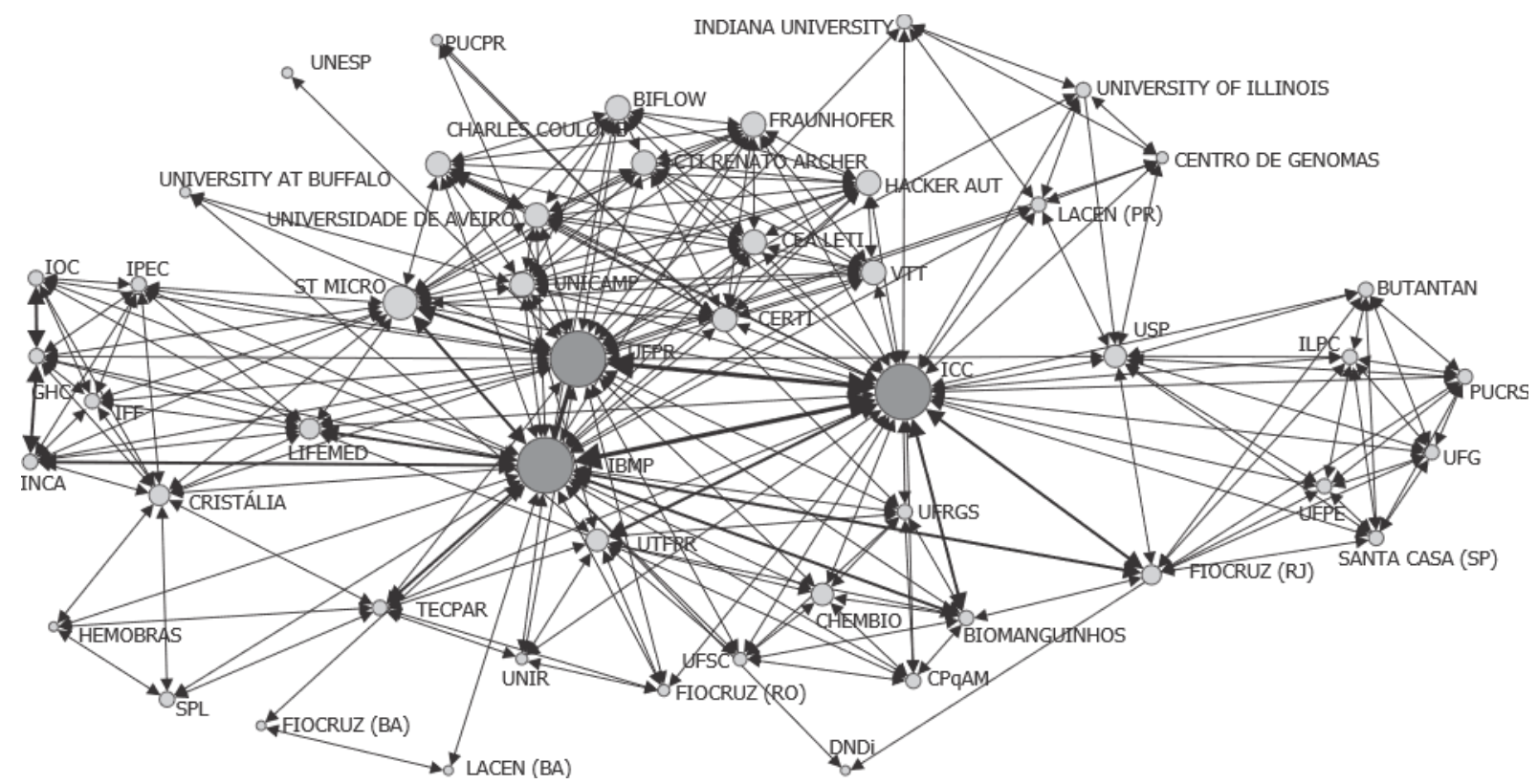

Figure 2. Research and innovation network from 2008 to 2014 
Concerning the INDI-Saúde's idea innovation network mode of coordination, we observed that it presents the more complex mode of coordination (Hage \& Hollingsworth, 2000). The data analysis showed that in the case we investigated, it is possible to observe from multiple organizations in a single arena to multiple arenas in a single organization, with Fiocruz Rio being the only organization being identified in all the six research arenas. However, we noticed through interview data that the network governance was centered in a hub formed by the Fiocruz Paraná arrangement, i.e., IBMP and ICC. The amount of public investment and the high levels of asset and knowledge specificity of the network were the conditions that led to the governance centered in hub organizations (Provan \& Kenis, 2008; Provan \& Milward, 2001).

As Hage, Mote, and Jordan (2013) addressed, when public and private investments in a particular area increase (in our case, in public health), the idea innovation network model may be predictive for innovation, since some patterns may emerge. As predicted by the authors, we observed that the sector became more complex and differentiated, occurring differentiation between the arenas, new high-technology companies, and research organizations arose within the arenas (new startups and spin-offs were born from the INDI-Saúde), and new research areas were developed, such as nanobiotechnology in this case. Furthermore, the complexity in the sector increased with the formation of sub-networks within and between arenas, increasing the connectedness in the network. In the next sections, we discuss how this pattern occurred in the INDI-Saúde network by means of two main dimensions of analysis, network shape, and connectedness.

\section{The INDI-Saúde's idea innovation network shape}

The network shape was assessed using three main variables: the number of researchers involved in each project, the kinds and quality of the results, and the amount of public and private expenditures. However, we argue that in the case we investigated, given the phenomenon of public funding to innovation and technological development, the economic outcomes are not the most important, being the effectiveness assessed through the satisfaction of the needs and the delivering of services for the broader society (Provan \& Milward, 2001). Thus, we found that the focus of the network led by ICC and IBMP as Fiocruz Paraná arrangement was the production of diagnosis' kits for reducing the public dependency of multinational labs, especially regarding the production inputs. In this sense, according to the research participants, the idea innovation network priority was to guarantee the supply of such production inputs for the SUS, especially the ones with lower levels of economic attractiveness.

We summarized the network shape assessment in Table 4. Concerning the first variable, the number of researchers, our data showed that the INCT INDI-Saúde alone had 42 researchers in eight different organizations. Of these researchers, 7 
were CNPq's Research Productivity Fellows (PQ), an individual grant awarded only to top researchers with outstanding production in their fields (Lima et al., 2015). Regarding the second variable, the INDI-Saúde network graduated 15 researchers (14 M.Sc., and 1 Ph.D.) from the 2008-2013 timespan, given that $15 \mathrm{kept}$ linked to the project, 8 as doctorate students in their Graduate School, 3 were hired as IBMP's researchers, the ICC hired 1, and 2 of them continued with INDI-Saúde's fellowships. These numbers revealed that the network is providing the system with qualified labor for public health, absorbing part of this workforce for feedbacking the research, technological development, and innovation chains.

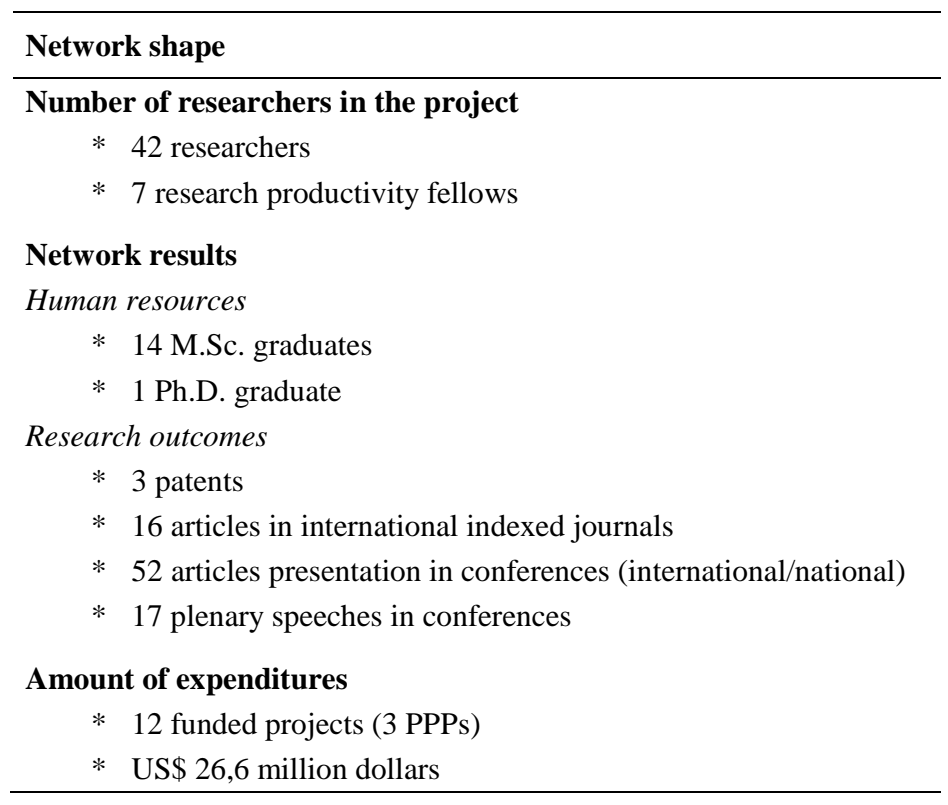

Table 4. Assessment of the idea innovation network shape

Furthermore, the innovation network efforts resulted in the granting of one joint patent of UFPR, Fiocruz, Federal University of Rio Grande do Sul (UFRGS) and IBMP, and two more patent deposits in the first five years of the project. Considering that in biotechnology the incentive system for technology development and patenting is recent, being the time for patent granting ranging from six to eleven years (Miranda, 2016; Ryan, 2010), this amount of patent applications from INDI-Saúde is considerably adequate for the timespan. Additionally, 15 articles were presented in international conferences, 37 articles were presented in national level conferences, 16 articles were published in international indexed journals, and more 17 plenary speeches in conferences.

The third variable for assessing the network shape is the amount of expenditure invested in the projects. In this sense, our data analysis showed that in the first five years of the project, there was an amount of US\$26.6 million dollars invested in twelve sub-projects that were part of the idea innovation network. Three of these projects were Public-Private 
Partnerships (PPPs): Stork Network, with Lifemed; Sepsis Network, with Lifemed, ST Microelectronics, and Cristália; and Fibrine Glue, with Cristália. The other nine projects were funded exclusively by public subvention. The actors involved in the innovation network argued that the amount of funding invested in the projects on the INDI-Saúde consequence of the capability of the network managers (ICC and IBMP) in taking advantage of their legitimacy in the field and operational efficacy in the collection of grants available in distinct sources. In this sense, we were able to observe what Hage, Mote, and Jordan predicted (2013), that the increasing of investments led to the patterns that are characteristic of idea innovation networks. Thus, in the following section, we analyzed the second dimension of the idea innovation network model: network connectedness.

\section{The INDI-Saúde's idea innovation network connectedness}

The network connectedness is related to the strength of ties among the actors participating in the network. The rationale is that the higher the frequency and intensity of interactions among the actors within and between different arenas, the higher the amount and quality of tacit and explicit knowledge exchange, enhancing, then, the likelihood of radical innovation (Hage \& Hollingsworth, 2000). The first criteria we observed for assessing idea innovation network connectedness were the transfer of people from one research group to another, within and between organizations, and face-to-face collaborations (distinct from long distance collaborations).

Our results showed that the formal transfer of researchers within and between organizations in INDI-Saúde were a commonplace in four specific initiatives: (i) in the efforts for optimizing the antigens of the Luminex system, in which we observed the transfer of human resources from ICC, Aggeu Magalhães Research Center (CPqAM/Fiocruz), BioManguinhos, and IBMP; (ii) in the development of the lab-on-a-chip as an alternative device for the commercial solution developed by Chembio, which involved researchers from UFPR and UTFPR; (iii) in the production and marking of polystyrene microspheres, involving researchers from UFRGS and Federal University of Santa Catarina (UFSC); and (iv) in the development of non-linear optics experiments, in which we found records of collaboration among UFPR, UTFPR, Federal University of Pernambuco (UFPE) and the Photonics INCT. The exchange among these organizations within and across organizations resulted from the division in specific research arenas, showing the strong associations among basic research arena (Arena 1), applied research arena (Arena 2), and product development and innovation research arena (Arena 3). 
Regarding the second variable for network connectedness, face-to-face collaboration, we noticed that it was limited to researcher's geographical distribution. The intensive face-to-face collaboration was perceived only in the epicenter of the idea innovation network, Curitiba, especially among ICC, IBMP, UFPR, and UTFPR. As the research participants narrated, at the time of creation of the INDI-Saúde network they perceived a high level of complexity and multidisciplinarity in the project. Thus, they decided to regularly meet in person for studying together to converge the methods and knowledge inherent to each other's disciplines, especially physics, chemistry, electrical engineering, and molecular biology. When the collaboration involved researchers from outside the limits of the state of Paraná, the contacts were limited to video conferences, phone calls, and, exceptionally, work meetings.

Finally, the last variable for assessing network connectedness was joint publications. Our analysis considered the permanent publications (indexed journals, $\mathrm{n}=16$ ) that were originated from INDI-Saúde's research and projects. We present the results in the sociogram representing the core-periphery network of joint publications from 2008-2014 (Figure 3). In the core of the network, we found a strong-tie relationship between UFPR (Physics and Chemistry Departments) and UTFPR (Electrical Engineering Department), with 3 joint publications in the period. UFPR is the most central actor in the network, being succeeded by ICC and IBMP, which have 2 joint publications between them. Unexpectedly, we found that a private organization, Centro de Genomas Lab, was located in the core of the network, contributing to the publications of two articles in collaboration with ICC, University of São Paulo (USP), UFPR, Central Laboratory of Paraná State (LACEN-PR), Indiana University, and University of Illinois.

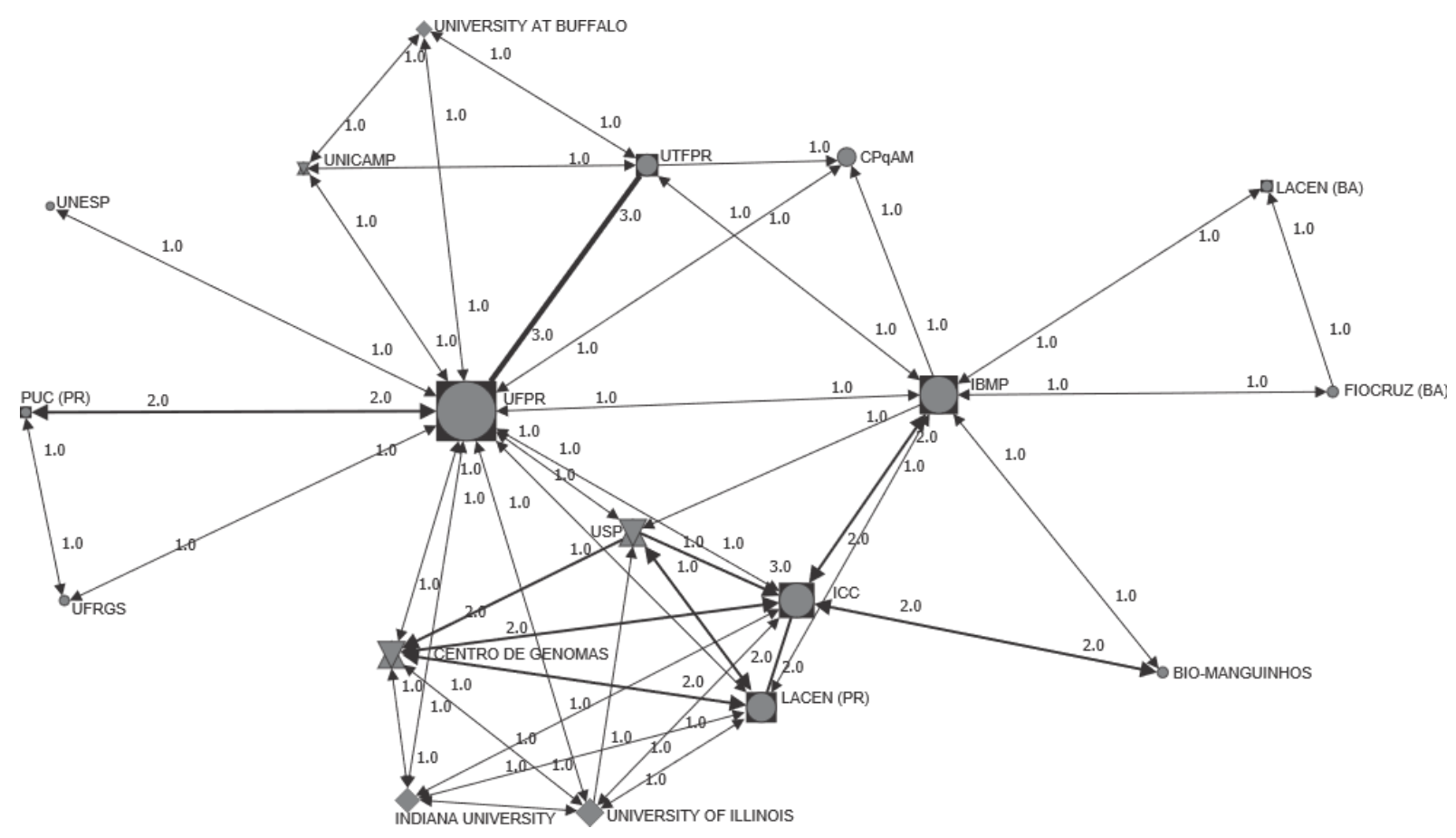

Figure 3. Core-periphery network of joint publications in the scope of the INCT INDI-Saúde 
After analyzing the network shape and network connectedness of INDI-Saúde's network, in the following section, we explored the idea innovation network structurally, especially concerning the relationships within and between arenas, and the developmental stage of each arena proposed in the model of Hage and Hollingsworth (2000).

\section{INDI-Saúde's idea innovation network and the six functional research arenas}

We performed the analysis of the idea innovation network by means of a binary affiliation matrix. Thus, based on the arguments of Hanneman and Riddle (2005), we started our analysis with a correspondence analysis, since this should be the adequate technique for 2-mode data. In this analysis, we aimed to identify the relations between actors (organizations in the network) and events (functional research arenas). The output of the correspondence analysis was a scatterplot, in which we could observe a higher concentration of actors around the Arenas 2 (applied research arena) and 3 (product development and innovation arena), and a low concentration of actors around Arenas 5 (quality control research arena) and 6 (commercialization research arena). The correspondence map also showed that the Arena 1 (basic research arena) concentrates the most of the universities and that the most of industrial organizations and laboratories are located around the Arena 4 (production research or process innovation arena).

For reducing dimensionality problems inherent of the 2-dimensional correspondence map (Borgatti \& Everett, 1997), we performed the analysis with a bipartite graph analysis (Figure 4), which allowed us to identify which organizations were located in which research arenas. Our analysis provided us with evidence to argue that in the idea innovation network of the INDI-Saúde there was a strong connectedness both within and between arenas, given that in every single arena there is at least one actor with relationships with actors located in other research arenas. In this sense, we state that the relationships between arenas were characterized by actors acting as structural holes of the network (Burt, 1992), being carriers of non-redundant and specialized knowledge and information from one specific arena to another. Additionally, the relationships within arenas were dense and closed (the actors frequently know and work with each other), tending to facilitate the flow and reliability of the information and knowledge in specific areas (Coleman, 1988; Krackhardt, 1992). 


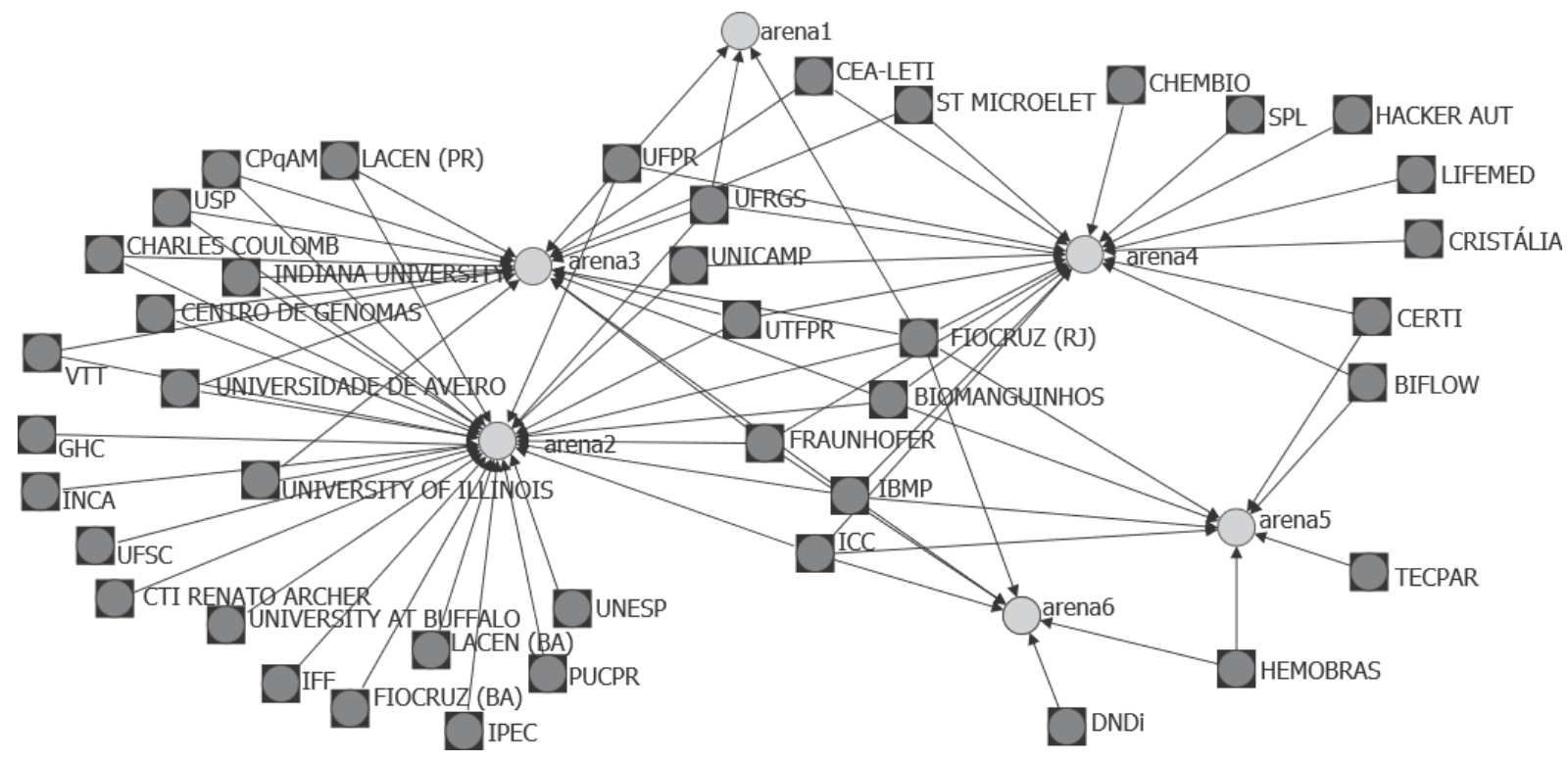

Figure 4. Bipartite graph (2-mode) of the network of relations between organizations and functional research arenas (2008-2014).

In this case, we found support for the argument that breakthrough innovation is closely related to major advancement in the basic sciences (Hage \& Hollingsworth, 2000). Even though the denser Arenas were the 2 and 3, the more prominent and innovative actors also transited by Arena 1, with an exception for the case of the IBMP itself. However, the ICC members, which are closely tied to the IBMP, are leading actor in the Arena 1. It was clear in our analysis when the research participants narrated that the innovation outcomes of the INDI-Saúde network were only possible due to the advances in the knowledge of basic sciences, such as physics, chemistry, and biology (e.g. the DNA genetic sequencing that was fundamental for the development of the NAT diagnostic tests).

We found that the connectedness between arenas was relevant because the knowledge developed in the Arenas 1 and 2 naturally flowed to organizations located in the Arenas 3 and 4, arenas which are the locus of technological development and in which are located the R\&D sectors of laboratories and private industries. We observed that the Arenas 5 and 6 had more relevance when the technological development reached the end of the innovation chain. For instance, Tecpar played a key role in the research and application of quality standards (Arena 5), being a reference in this area. Regarding distribution and commercialization of the innovation outputs, the diagnostics kits were taken into the SUS by organizations like Fiocruz and Hemobrás, which were closer to the demanding actors (i.e. the Brazilian Ministry of Health).

The last step of the analysis was the identification of the stage of development of each arena. We conducted this analysis by means of a core-periphery blockmodeling (Table 5). This analysis consists of a partition of the data into two main blocks, in which in the central block (core) are located the actors and events with higher levels of co-occurrence. The 
blockmodel provided us with further evidence for the findings we had through the correspondence analysis and the bipartite graph analysis. We found that there was a higher concentration of actors in the Arenas 2, 3, and 4 (Density=0.879).

Furthermore, the most central actors of the network were located primarily in these functional research arenas, being less attached to the second block (periphery) consisting in the Arenas 1, 5, and 6 (Density=0.343). The blockmodel also showed us that the most peripheric actors were residually located in the second block of functional research arenas (Density=0.071), being more active in the Arenas 2, 3, and 4 (Density=0.391). These findings lead us to argue that the less prominent actors of the network are more likely to be located close to central and powerful actors, guaranteeing them access to resources and information that they would not be able to access if located in less developed arenas.

\begin{tabular}{lcccc}
\hline \multicolumn{2}{l}{ Goodness-of-fit } & \multicolumn{3}{c}{ Density matrix } \\
Starting fitness: 0.701 & \multicolumn{2}{c}{1} & 2 \\
Final fitness: & 0.786 & 1 & 0.879 & 0.343 \\
& & 2 & 0.391 & 0.071
\end{tabular}

Blocked Adjacency Matrix

\begin{tabular}{|c|c|c|c|c|c|c|}
\hline & 4 & 2 & 3 & 1 & 5 & 6 \\
\hline & $\mathrm{a}$ & $\mathrm{a}$ & $\mathrm{a}$ & $a$ & $\mathrm{a}$ & $\mathrm{a}$ \\
\hline ICC & 1 & 1 & & & 1 & 1 \\
\hline FIOCRUZ (RJ) & 1 & 1 & 1 & 1 & 1 & 1 \\
\hline UFPR & 1 & 1 & 1 & 1 & & \\
\hline IBMP & 1 & 1 & 1 & & 1 & 1 \\
\hline UFRGS & 1 & 1 & 1 & 1 & & \\
\hline UTFPR & 1 & 1 & 1 & & & \\
\hline INDIANA UNIVERSITY & & 1 & 1 & & & \\
\hline BIOMANGUINHOS & 1 & 1 & 1 & & 1 & 1 \\
\hline CEA-LETI & 1 & & 1 & & & \\
\hline FRAUNHOFER & 1 & 1 & 1 & & & 1 \\
\hline UNIVERSITY OF ILLINOIS & & 1 & 1 & & & \\
\hline $\begin{array}{lll} & \text { VTT }\end{array}$ & & 1 & 1 & & & \\
\hline USP & & 1 & 1 & & & \\
\hline UFSC & & 1 & & & & \\
\hline LIFEMED & 1 & & & & & \\
\hline HACKER AUT & 1 & & & & & \\
\hline UNIVERSIDADE AVEIRO & & 1 & 1 & & & \\
\hline CHARLES COULOMB & & 1 & 1 & & & \\
\hline CPqAM & & 1 & 1 & & & \\
\hline CTI RENATO ARCHER & & 1 & & & & \\
\hline CERTI & 1 & & & & 1 & \\
\hline UNICAMP & 1 & 1 & & & & \\
\hline CHEMBIO & 1 & & & & & \\
\hline CRISTALIA & 1 & & & & & \\
\hline INCA & & 1 & & & & \\
\hline IFF & & 1 & & & & \\
\hline IPEC & & 1 & & & & \\
\hline GHC & & 1 & & & & \\
\hline HEMOBRAS & & & & & 1 & 1 \\
\hline TECPAR & & & & & 1 & \\
\hline
\end{tabular}




\begin{tabular}{|c|c|c|c|c|}
\hline 31 & SPL & 1 & & \\
\hline 32 & DNDi & & & 1 \\
\hline 33 & CENTRO DE GENOMAS & 1 & 1 & \\
\hline 34 & UNIVERSITY AT BUFFALO & 1 & & \\
\hline 15 & ST MICROELET & 1 & 1 & \\
\hline 36 & LACEN (BA) & 1 & & \\
\hline 37 & FIOCRUZ (BA) & 1 & & \\
\hline 38 & LACEN (PR) & 1 & 1 & \\
\hline 19 & BIFLOW & 1 & & 1 \\
\hline 40 & UNESP & 1 & & \\
\hline 41 & PUCPR & 1 & & \\
\hline
\end{tabular}

Table 5. Core-periphery blockmodeling between organizations and functional research arenas in the INDI-Saúde network.

Regarding the quality of the blockmodeling procedure, the model originated from the matrix of functional research arenas was significant, since the final goodness-of-fit of 0.786 was considered high by the literature standards (Hanneman \& Riddle, 2005). Another indicator of the fitness of the model was the evaluation of the density matrix. In this sense, the core block 1,1 (containing the most central actors of the network and the most concentrated arenas) should present a density value close to one, and the periphery block 2,2 (containing the most peripheric actors in the least occurrent arenas) should present a density value close to zero (Hanneman \& Riddle, 2005). Thus, per our assessment, the blockmodel was considered significant for the INDI-Saúde's network case.

Finally, we found that the network managers did not deliberate to be organized in the form of idea innovation network (organized into functional research arenas). However, our findings showed that the INDI-Saúde network presented the emergence of the characteristics of this mode of network organization. Concerning the stage of development of the functional research arenas, our findings allowed us to divide them into three distinct groups: (i) consolidated arenas; (ii) arenas in advanced stage of consolidation; and (iii) arenas in the primary stage of consolidation. Our data analysis showed that the Arenas 2 (applied research arena) and 3 (product development or product innovation) were components of the first block, the consolidated/developed arenas. The Arena 4 (production research or process innovation arena) presented an advanced stage of consolidation since the integration between research organizations and universities with private labs and industries were increasing. The Arenas 1 (basic research arena), 5 (quality control research arena), and 6 (commercialization research arena) were still on a transition from primary to intermediary stage of consolidation/development, since they concentrated specific kinds of organizations presenting connectedness with organizations across their arenas, but with a nascent stage of connectedness within their own arenas. 


\section{Concluding remarks}

Our analysis of the INDI-Saúde case showed that the idea innovation network model might be adequate in the Brazilian context of innovation for public health. During our investigation, we could not only understand how this kind of network works but also understand how they were formed and evolved into a fruitful initiative for technological development and innovation in molecular biology. Thus, we agree with the argument that idea innovation networks may present a predictive character for innovation (Hage et al., 2013) when organized in connected research arenas. Our argument is directed by the fact that beyond producing patents and scientific publications, the INDI-Saúde network gave birth to successful spinoffs and startups.

In what refers to idea innovation network shape, we found that the high amount of resources invested potentialized the capability of development of the network, providing a certain pattern of development in each of the six functional research arenas that characterize the model. Regarding idea innovation network connectedness, we contributed for demonstrating empirically that the INDI-Saúde network presented different structural characteristics when comparing the patterns of relationships within and between arenas. On relationships within arenas, we observed dense and closed networks, presenting strong ties between the actors, and providing trust and deepness of the information and knowledge flow within the arenas (Coleman, 1988; Krackhardt, 1992). On the other hand, we observed sparser networks between arenas, with actors using weak ties for playing roles of structural holes in the network, taking non-redundant and specific knowledge to other arenas (Burt, 1992; Granovetter, 1973).

Regarding the functional research arenas, our study led us to agree with Hage and Hollinsworth's (2000) argument that radical innovation is closely linked to advances in basic research, represented by the Arena 1 . For instance, in our investigation on INDI-Saúde's network, advances in biology, chemistry, and physics were fundamental for the development of molecular diagnostic tests for public health like the NAT. However, we found that innovation is more likely to occur when the knowledge and information created in the Arena 1 flow across the basic research arena, passing through the applied research arena, and product and process innovation arenas (Arenas 2, 3, and 4). The relevance of this arenas compared to the least developed ones $(1,5$, and 6$)$ showed that they are crucial for technological development and innovation.

Another contribution of our study was the definition of the distinct possible stages of development of the functional research arenas, expanding the idea innovation network model (Hage \& Hollingsworth, 2000). Thus, we proposed that the functional arenas may not be equally developed, once we found consolidated arenas ( 2 and 3 ), one arena in advanced 
developmental stage (Arena 4), and three other arenas in preliminary development stage (1, 5, and 6). Another finding is related to the kind of organizations that are located within the arenas. In the basic research arena, we found that universities and public research organizations were predominant, reflecting the Brazilian national system of innovation. On the other hand, the arena closer to the firm's $R \& D$, the Arena 4, were the locus for private labs and industrial organizations.

Our investigation also presented contributions for practitioners. Since the idea innovation network was not deliberately created with the six functional research arenas, we argue that if new networks are formed contemplating this model, the innovation will be more likely to occur, and in shorter time span (Hage et al., 2013). In this sense, public policy programs could be benefited of our findings, promoting the formation of networks with potentially positive results on technological development and innovation, especially regarding public health.

We recognize that our study has limitations. First, we aimed to analyze the INDI-Saúde's network on the light of the idea innovation network model even under circumstances of lack of empirical validation, since the model was only theoretically developed, and in a context diverse than the one it was thought (Hage \& Hollingsworth, 2000; Van de Ven et al., 2000). Second, we were only able to analyze the idea innovation due to interview data, given that the lack of culture for Brazilian organizations to provide documentary data prevented us from gathering access to specific financial and contractual data that could provide us with stronger evidence for the case study. And, finally, we developed our methods for investigating idea innovation networks with SNA techniques, however, we could not assess variables such as the effective size for measuring structural holes (Burt, 1992), or even the E-I index for analyzing the interaction objectively within and between research arenas (Hanneman \& Riddle, 2005; Krackhardt \& Stern, 1988).

Considering that our study was located on public health context, we argue that there is a possible avenue for future studies to expand our research regarding innovation results, especially when taking into account those results that are not fundamentally economic (Provan \& Milward, 2001). In this sense, we encourage future studies to investigate results as additionalities, such as (1) input additionalities, researching the ratio of private investment compared to public investments; (2) output additionalities, investigating the extent which the results would be achieved without public funding; or (3), behavioral additionality, researching the extent which the public financing influenced the behavior of organizations in what refers to research and development (Georghiou \& Clarysse, 2006).

\section{References}


Belussi, F., \& Sedita, S. R. (2009). Life cycle vs. multiple path dependency in industrial districts. European Planning Studies, 17(4), 505-528.

Bonfim, L. R. C., Gonçalves, S. A., Moreira, M. S., \& Jacometti, M. (2016). Institutional Entrepreneurship and Improvement of Quality of Life: the formation and legitimation of a public-private innovation network in molecular biology applied to public health in Southern Brazil. In J. C. C. Leitão \& H. M. B. Alves (Eds.), Innovative and entrepreneurial practices in public institutions: a quality-of-life approach (pp. 123-154). Cham: Springer.

Borgatti, S. P. (2002). NetDraw Software for Network Visualization. Lexington, KY: Analytic Technologies.

Borgatti, S. P., \& Everett, M. G. (1997). Network analysis of 2-mode data. Social Networks, 19(3), 243-269.

Borgatti, S. P., Everett, M. G., \& Freeman, L. C. (2002). Ucinet for Windows: Software for social network analysis.

Burt, R. S. (1992). Structural holes: the social structure of competition. In R. G. Eccles \& N. Nohria (Eds.), Network and organizations: structure, form and action (pp. 57-93). Boston, MA: Harvard Business School Press.

Castilla, E. J., Hwang, H., Granovetter, E., \& Granovetter, M. (2000). Social networks in silicon valley. In C. M. Lee, W. F. Miller, M. G. Hancock, \& H. S. Rowen (Eds.), The Silicon Valley edge: A habitat for innovation and entrepreneurship (pp. 218-247). Stanford, CA: Stanford University Press.

Coleman, J. S. (1988). Social capital in the creation of human capital. American Journal of Sociology, 94(Supplement), S95-S120.

Cusumano, M. A., Mylonadis, Y., \& Rosenbloom, R. S. (1992). Strategic Maneuvering and Mass-Market Dynamics: The Triumph of VHS over Beta. Business History Review, 66(1), 51-94.

Flick, U. (2009). An introduction to qualitative research. London, UK: Sage Publications.

Georghiou, L., \& Clarysse, B. (2006). Introduction and Synthesis In Organisation for Economic Co-operation and Development (Ed.), Government R\&D Funding and Company Behaviour: Measuring Behavioural Additionality (pp. 938). Paris: OECD Publishing

Gibbs, G. R. (2007). Analysing qualitative data. London, UK: Sage.

Granovetter, M. S. (1973). The Strength of Weak Ties. American Journal of Sociology, 78(6), 1360-1380.

Hage, J., \& Hollingsworth, J. R. (2000). A strategy for the analysis of idea innovation networks and institutions. Organization Studies, 21(5), 971-1004.

Hage, J., Mote, J. E., \& Jordan, G. B. (2013). Ideas, innovations, and networks: a new policy model based on the evolution of knowledge. Policy Sciences, 46(2), 199-216.

Hanneman, R. A., \& Riddle, M. (2005). Introduction to social network methods. Riverside, CA: University of California Riverside.

Hollingsworth, J. R. (2000). Doing institutional analysis: implications for the study of innovations. Review of International Political Economy, 7(4), 595-644.

Jacometti, M., Gonçalves, S. A., \& Castro, M. d. (2014). Institutional work e conhecimento em redes interorganizacionais: uma proposta para investigar APLs. Revista de Administração Mackenzie, 15(6), 17-47.

Kline, S. J., \& Rosenberg, N. (1986). An overview of innovation. In R. Landau \& N. Rosenberg (Eds.), The positive sum strategy: harnessing technology for economic growth (pp. 275-305). Washington, DC: National Academy Press.

Krackhardt, D. (1992). The strength of strong ties: the importance of philos in organizations. In N. Nohria \& R. G. Eccles (Eds.), Networks and Organizations: Structure, Form, and Action (pp. 216-239). Boston, MA: Harvard Business School Press. 
Krackhardt, D., \& Stern, R. N. (1988). Informal networks and organizational crises: An experimental simulation. Social Psychology Quarterly, 51(2), 123-140.

Kraft, K., Stank, J., \& Dewenter, R. (2011). Co-determination and innovation. Cambridge Journal of Economics, 35(1), 145-172.

Krieger, M. A., Souza, R., Alvarez, P., Ferreira, A., \& Moreira, M. S. (2013). Cooperação técnico-científica entre instituições públicas e privadas para incorporação tecnológica: impacto da nacionalização do teste NAT HIV e HCV na ampliação do acesso e na formação de base tecnológica no âmbito do Sistema Único de Saúde. Divulgação para Saúde em Debate, 50, 102-112.

Lima, H., Silva, T. H., Moro, M. M., Santos, R. L., Meira Jr, W., \& Laender, A. H. (2015). Assessing the profile of top Brazilian computer science researchers. Scientometrics, 103(3), 879-896.

Loyola, M. A. (2008). Medicamentos e saúde pública em tempos de AIDS: metamorfoses de uma política dependente. Ciência \& Saúde Coletiva, 13(Suplementar), 763-778.

Merriam, S. B. (2009). Qualitative Research: A Guide to Design and Implementation. San Francisco, CA: Jossey-Bass.

Miranda, L. (2016). Brazil's New Path to Meaningful Intellectual Property Protection. Inter-American Law Review, $48(2), 122-224$.

Porter, M. E. (2000). Location, competition, and economic development: Local clusters in a global economy. Economic development quarterly, 14(1), 15-34.

Powell, W. W., Koput, K. W., \& Smith-Doerr, L. (1996). Interorganizational collaboration and the locus of innovation: Networks of learning in biotechnology. Administrative Science Quarterly, 41(1), 116-145.

Prithwiraj, C., James, A., \& Tarun, K. (2012). A ‘core-periphery’framework to navigate emerging market governments - qualitative evidence from a biotechnology multinational. Global Strategy Journal, 2(1), 71-87.

Provan, K. G., \& Kenis, P. (2008). Modes of network governance: structure, management, and effectiveness. Journal of Public Administration Research and Theory, 18(2), 229-252.

Provan, K. G., \& Milward, H. B. (2001). Do networks really work? A framework for evaluating public-sector organizational networks. Public Administration Review, 61(4), 414-423.

Rezaie, R., Frew, S. E., Sammut, S. M., Maliakkal, M. R., Daar, A. S., \& Singer, P. A. (2008). Brazilian health biotech: fostering crosstalk between public and private sectors. Nature Biotechnology, 26(6), 627-644.

Rezende, S. M. (2011). Produção científica e tecnológica no Brasil: conquistas recentes e desafios para a próxima década. Revista de Administração de Empresas, 51(2), 202-209.

Rowley, T., Behrens, D., \& Krackhardt, D. (2000). Redundant governance structures: An analysis of structural and relational embeddedness in the steel and semiconductor industries. Strategic Management Journal, 21(3), 369-386.

Ryan, M. P. (2010). Patent Incentives, Technology Markets, and Public-Private Bio-Medical Innovation Networks in Brazil. World Development, 38(8), 1082-1093.

Van de Ven, A. H. (1986). Central problems in the management of innovation. Management Science, 32(5), $590-607$.

Van de Ven, A. H., Angle, H. L., \& Poole, M. S. (2000). Research on the management of innovation: The Minnesota studies. New York, NY: Oxford University Press.

Van Waarden, F., \& Oosterwijck, H. (2006). Turning tracks? Path dependency, technological paradigm shifts, and organizational and institutional change. In J. Hage \& M. Meeus (Eds.), Innovation, science, and institutional change (pp. 443-464). Oxford, UK: Oxford University Press. 
Wasserman, S., \& Faust, K. (1994). Social network analysis: Methods and applications. New York, NY: Cambridge University Press. 